\title{
Exploring environmental sustainability of academia as a working space.
}

\author{
STAVRIANAKIS, K. and RAMOS, W.
}

2022

This author accepted manuscript is deposited under a Creative Commons Attribution Non-commercial 4.0 International (CC BY-NC) licence. This means that anyone may distribute, adapt, and build upon the work for non-commercial purposes, subject to full attribution. If you wish to use this manuscript for commercial purposes, please contact permissions@emerald.com. 


\title{
Exploring Environmental Sustainability of Academia as a Working Space
}

*Kostas Stavrianakis, kstavria@iu.edu, Robert Gordon University, Aberdeen Business School William Ramos, wramos@indiana.edu, , Indiana University Bloomington, School of Public Health, Department of Health and Wellness Design

*Corresponding author

Submission: $1 / 2 / 21$

Revised:22/4/21

Submission:21/6/21

Revised: $12 / 8 / 21$

\begin{abstract}
One of the roles of academia is to prepare well-informed and responsible citizens. From a sustainability perspective, academia leads the way in producing research supporting environmental sustainability, but little is known about whether sustainability is being practiced within the institutions and amongst faculty members overall. The purpose of this study is to examine the organizational citizenship behaviors toward the environment among US-based faculty members with different academic backgrounds. Potential barriers preventing academia from being more sustainable are identified, as well as opportunities for academics to be involved in environmental sustainability are discussed. This study employed a mixed methods approach collecting survey responses $(n=633$ and conducting phone interviews $(n=28)$ with academics engaging in research or teaching in different academic disciplines. Results suggest that there are certain power dynamics that force young faculty members into anti-environmental behaviors, although they are cognizant of the negative impacts on the environment. Many faculty members engage in environmental-related actions outside their service requirements, but this is mostly the case for tenured faculty members. The originality of this study lies on the fact that it explores environmental behaviors from an academic ranking perspective and expands on pertinent barriers to promote sustainable behaviors in academia.
\end{abstract}


Keywords: Cognitive Dissonance; Mixed Methods; Flying; Academics; OCBE

\section{Introduction}

The constant degradation of the natural environment due to resource exploitation by human activities has been recognized and acknowledged by many scholars from a range of disciplines (Dunlap et al., 1983; Gardner \& Stern, 1996; Ostrom, 2009). The realization of the consequences that humans have on the natural environment has led scholars to study human-environment interactions by studying peoples' environmental behaviors (EB). Asserting that every single person has an impact on the natural environment (Klaniecki et al., 2018), it is important to expand environmental behavior studies into traditionally unstudied groups, such as academics. There is a plethora of studies exploring the EB of social groups, such as teachers, students, and farmers, including studies by (Ateş, 2020; Fang, Ng, \& Zhan, 2018; Janmaimool \& Khajohnmanee, 2019), but there is a gap in understanding academics' EB. The purpose of this study is to address that gap and extend our understanding of academics' EB in their work setting, i.e., academia. Although there is some research available on academics and EB, most findings are based on quantitative data, such as the findings from Choong et al. (2020) and Fawehinmi, Yusliza, Mohamad, Faezah, and Muhammad (2020). In their study, Fawehinmi et al. (2020), suggested that human resource management can have a positive impact on the EB of academics through the transmission of environmental knowledge. In another study, Choong et al. (2020), have suggested that, if institutions want to enhance their EB, they should have in place policies and procedures that can accommodate an active and green work environment. The authors also 
discuss the importance of creating a working environment that instigates a harmonious environmental passion. A harmonious environmental passion is defined by Robertson and Barling (2013) as "a positive emotion that results in an individual wanting to engage in proenvironmental behaviors" (p. 180).

This study employs a mixed method approach to further understand academics' environmental sustainability by identifying some of the barriers that prevent academics from being more sustainable.

The objective of this study is to explore the environmental behaviors of US-based academics that teach or do research on environmentally related issues and identify possible barriers to being more sustainable. As EB are mostly studied from the perspective of everyday behaviors, there is a gap in our understanding of EB in workplaces (Ones \& Dilchert, 2012). This paper aims to address this gap. This study takes into consideration the voluntary actions that academics perform as employees to promote sustainability and identifies potential barriers associated with the promotion of sustainability.

To achieve the above, the authors followed a mixed methods approach informed by the organizational citizenship behavior for the environment (OCBE) paradigm. Although OCBE has been used in different professional contexts, including tourism, business administration, manufacturing corporations, and financial institutions, little is known about OCBE and academia. In addition, this study uses cognitive dissonance as the theoretical framework to try and explain reported behaviors.

\section{Literature review}

\subsection{What influences Environmental Behaviors?}


An environmental behavior can be one that either leads to the protection and conservation of the natural environment - a Pro-Environmental Behavior (PEB) - or a behavior that has a negative impact and results in the degradation of the natural environment - an AntiEnvironmental Behavior (AEB). There are several synonyms to PEB, including, but not limited to, sustainable behaviors, ecological behaviors, and environmentally related behavior (Kurisu, 2015). This study used the definition of PEB by Kollmuss and Agyeman (2002) as "the behavior that consciously seeks to minimize the negative impact of one's actions on the natural and built world" (p. 240), such as limiting the usage of plastic bags.

The different elements that influence individuals' environmental behaviors have been extensively studied, with researchers reporting amongst others the importance of values, knowledge, emotion, and social norms (Kollmuss \& Agyeman, 2002). According to Kollmuss and Agyeman (2002), the three elements that can influence EB are: 1) demographics, 2) external factors (e.g., infrastructure, social, and structural norms), and 3) internal factors (e.g., emotions, values, and knowledge). Recent work on the above three elements will be reviewed below.

In a recent study in Malaysia, researchers found that demographics like education and gender had a positive impact on EB, while income did not (Chekima, Chekima, Syed Khalid Wafa, Igau, \& Sondoh Jr, 2016). Similar findings were reported from a study in the Netherlands (De Silva \& Pownall, 2014). The role of income has been discussed in several studies with mixed results. Hazal Aral and López-Sintas (2020) reported that affluent individuals were more likely to purchase eco-friendly products, but income had little impact on their choice of using public transportation or not. Meyer (2016) reported that college students with higher income were less likely to use double sided printing. In a study conducted in China, the authors reported that lower income families conserved more energy compared to higher income families (Yang, 
Zhang, \& Zhao, 2016); this reduction is mainly associated with monetary reasons and reducing energy bills.

In a study looking at waste disposal behaviors in Cambodia, the authors found that internal factors had a significant impact on individuals' waste behaviors (Srun \& Kurisu, 2019). The researchers reported that social norms and peer pressure had significant effects in their behavioral intentions in contrast to external factors, such as low collection frequency and low cleaning services. Chu (2018) explored how different internal and external factors might influence Chinese consumers to purchase organic food products. The author suggested that positive attitudes towards organic food bolsters consumers intentions to buy them, while external factors like marketing price and communication did not have a significant impact on participants' attitudes about organic food.

\subsection{Theoretical Framework}

Although many theoretical frameworks have been used in an attempt to explain EB, this study will explore Festinger's theory of cognitive dissonance in relation to academics' EB. According to Festinger (1957), individuals are in a cognitively dissonant state when they hold two or more contradictory beliefs leading to cognitive unbalance. For those individuals to regain cognitive balance, they need to justify the behaviors they choose to engage in or not. The three suggested ways that individuals can reduce their cognitive dissonance are: 1) change their beliefs, 2) change their behavior, and 3) justify their behavior (Harmon-Jones \& Mills, 1999). In addition, there are four paradigms associated with the mental stress of individuals when in cognitive dissonance: 1) belief disconfirmation (i.e., holding a belief that does not reduce dissonance and leads individuals to reject the belief that caused dissonance in the first place); 2) induced compliance (i.e., when the state of cognitive dissonance is due to external stimuli); 3) 
free choice (i.e., augmenting the importance of the choice individuals cognitively made while reducing the importance of the choices they did not select); and 4) effort justification (i.e., validating their efforts while undertaking an unpleasant duty) (Harmon-Jones, 2002; Shultz \& Lepper, 1996). In his paper, Thogersen (2002) suggests that individuals often fail to identify their inconsistencies between their beliefs and their consumption behaviors associated with sustainability. The researcher proposes the use of environmental education programs to inform citizens and consumers.

In the EB literature, cognitive dissonance has been explored in various contexts, including climate change, water conservation, sustainable tourism, and sustainable consumption (Dolnicar, Knezevic Cvelbar, \& Grün, 2017; Gadeikienè, Dovalienè, Grase, \& Banyte, 2019; Taylor, Lamm, \& Lundy, 2017). In a recent study, the authors reported certain levels of cognitive dissonance amongst sustainability scientists and their flight behaviors (Schrems \& Upham, 2020). The authors noted that, although participants were aware of the negative impacts their flying behaviors had on the environment, they continued to engage in that same behavior. Similar results were found by a study exploring the flying behaviors of academics in an Australian university. The authors reported that participants did not change their flying behaviors because there were no institutional incentives to do so (Nursey-Bray, Palmer, Meyer-Mclean, Wanner, \& Birzer, 2019). To our knowledge, other than the above cited studies, there is no other research exploring academics' EB through the lens of cognitive dissonance.

\subsection{Organizational Citizenship Behavior for the Environment}

This paper employed the OCBE paradigm to try to understand academics' EB as employees who are not required or obligated to participate in pro-environmental behaviors. According to Daily, Bishop, and Govindarajulu (2009), OCBE is defined as the "discretionary acts by 
employees within the organization not rewarded or required that are directed toward environmental improvement" (p. 246). Extensive research has been conducted looking at OCBE on an organizational level, with more recent studies looking at individual employees' motivations to promote EB (Tosti-Kharas, Lamm, \& Thomas, 2017).

In a study conducted by Luu (2017) exploring OCBE in the hospitality industry, findings suggest that individual pro-environmental behaviors at work can influence peers' proenvironmental behaviors, as well as the organizations' sustainability programs. In a separate study, Hameed, Khan, Islam, Sheikh, and Naeem (2020) reported that Green Human Resource Management has a positive impact on OCBE through the recognition and empowerment of employees' EB. Similar findings were reported by Anwar et al. (2020) and Gilal, Ashraf, Gilal, Gilal, and Channa (2019), who conducted their studies in a higher education setting. A gap that exists in the OCBE literature is understanding the motivations that lead employees and organizations to take environmentally sustainable actions (Tosti-Kharas et al., 2017). Some scholars suggest that protecting the natural environment is an individual's moral obligation (De Groot \& Steg, 2008), while other scholars indicate that organizations protect the natural environment for their organization's benefit, such as reputation and cost saving reasons (Porter \& Van der Linde, 1995).

It is widely accepted that environmental degradation is the result of anthropogenic impacts. Those impacts are being driven by industries and organizations that lead world economies and high-volume employers. Blok, Wesselink, Studynka, and Kemp (2015) reported workplaces as being very important settings for bolstering pro-environmental behaviors through leadership support. On average, employees work 90,000 hours in their life time, based on a 40 hour work week (Pryce-Jones, 2011). In academia, this number is likely higher, as academics tend to work 
more than 60 hours per week, according to Ziker (2014). As workplaces play an important role in our daily lives and our decision-making process, it is essential that we further understand the implications of workplaces sustainability and EB. According to Muster (2011) all individuals are part of different social contexts, with work being one of them, and they are important for shaping social norms and encouraging sustainable behaviors (Adam, 2018; Staddon, Cycil, Goulden, Leygue, \& Spence, 2016). As employees are also consumers while at work, it is important that companies shape and create an organizational culture that leads to sustainable behaviors, as those behaviors can be transferred to their private life (Muster, 2011; Programme, 2016), creating a spill-over effect (Gadeikienè et al., 2019).

As per Ones and Dilchert (2012), companies and organizations define their success on the same three pillars that sustainability is built upon: society, economy, and environment. For the companies to achieve the above organizational goals, they must adapt to new changes (Ones $\&$ Dilchert, 2012). Jabbour and Santos (2006) state that organizations can achieve environmental sustainability through three steps: 1) comply with the environmental regulations; 2) incorporate necessary measures to prevent environmental damage; and 3) engage in voluntary actions to enhance environmental sustainability. All the above require the presence and efforts of the employees and the employer.

As environmental problems become more abundant and apparent, companies and organizations are focusing on reducing their carbon footprint and positively contributing to the natural environment (Ones \& Dilchert, 2012). Pertinent literature on EB and working spaces suggests that, when employees are involved in sustainability programs and pro-environmental initiatives in their company, they have direct impacts in the reduction of pollutants and the development of more efficient environmental management systems in their companies (Ramus \& 
Killmer, 2007). However, it is often the case that employees must engage in these initiatives in order to reach an organizational goal or to be compliant with regulations and not necessarily from a personal incentive, as suggested by Jabbour and Santos (2006).

Studies that investigate the organization of academia are limited, even though the important role of university employees in promoting sustainability has been identified by several researchers. University employees' contributions to sustainability efforts have been studied, including the contributions of both academic and non-academic staff members (Bellou, Petreniti, \& Skanavis, 2017; Brinkhurst, Rose, Maurice, \& Ackerman, 2011; Fonseca, Macdonald, Dandy, \& Valenti, 2011). In their study, Yuriev and Sierra-Barón (2020) discussed the importance of the cultural context associated with workplace pro-environmental behaviors in universities and the necessity to look at EB individually, not grouped together. The importance of staff training and development in regard to promoting sustainability and OCBE is reported by Niyomdecha and Yahya (2019). Finally, Anwar et al. (2020) found that increased levels of OCBE resulted in higher environmental performance of a university campus in Malaysia.

Industries and organizations throughout the world have been shifting their management to embrace environmental sustainability. It is important that academia as an institution is leading the way, ensuring that employees have the opportunity to engage in sustainable practices. Academia has a distinct role in society.

\subsection{Role of Academia}

Apart from carrying out research on environmental issues and informing the public, academia is also responsible for providing individuals with the necessary tools to lead a sustainable lifestyle. In addition, universities prepare individuals to become world leaders, teachers, managers, and decision makers; thus, they need to equip them well for a sustainable 
future (Bekessy \& Burgman, 2003). At the same time, academia has been critiqued for being unsustainable. In his article, Baer (2019) comments on the importance of air travelling for academic anthropologists and points out their contribution to greenhouse gases. In the article, he urges for immediate changes in how academia operates (e.g., conferences) in order for the field to become more sustainable. In a comment response to Baer (2019), Dr. Hughes concurred with the content of the article and made his point for the need to travel less. Similar conclusions have been made by Burke (2010) and Glover et al. (2017) in regards to flying to participate in conferences. In addition, scientists from the natural science disciplines, such as geology, ecology, and conservation biology, are more likely to have a higher academic carbon footprint than social scientists due to the fact that they often have to fly to their research areas to perform the necessary ecological surveys and experiments (Fox et al., 2009). Ethnographers can have a similar impact because their data collection are often in regions away from their university.

There is a plethora of studies investigating the aspect of conferences and climate change (Caset et al., 2018; Desiere, 2016; Glover et al., 2017) but not the perception that academics have towards them. Further, air travel is not the only way in which conferences contribute to climate change; catering, tableware, and printing are other contributing factors. In a 2010 ecology conference with 125 participants, the carbon dioxide emissions was estimated to be 11.5 tons of carbon dioxide, out of which $66 \%$ were due to travelling (Bossdorf et al., 2010). The scientific community has recognized their environmental impact, and they are advocating for more sustainable practices (Bossdorf et al., 2010; Lester, 2007). Such practices include better choices of conference locations and teleconferences, among others.

Durr, Bilecki, and Li (2017) examined the relation between beliefs and participation in proenvironmental behaviors among university employees and university students. Their findings 
suggest that beliefs do not necessarily translate in engaging in pro-environmental behaviors.

Although the authors presented important findings that were aligned with previous studies, they did not explore in depth the barriers and the reasons why employees did not always act according to their beliefs.

\subsection{Study Purpose}

The purpose of this study is to examine whether academia is a sustainable working environment and the perceived barriers averting faculty members from being more sustainable.

Within this work, we explored the application of cognitive dissonance as a theoretical framework in understanding academics' environmental behaviors, as well the organizational citizenship behavior for the environment paradigm.

\section{Materials and Methods}

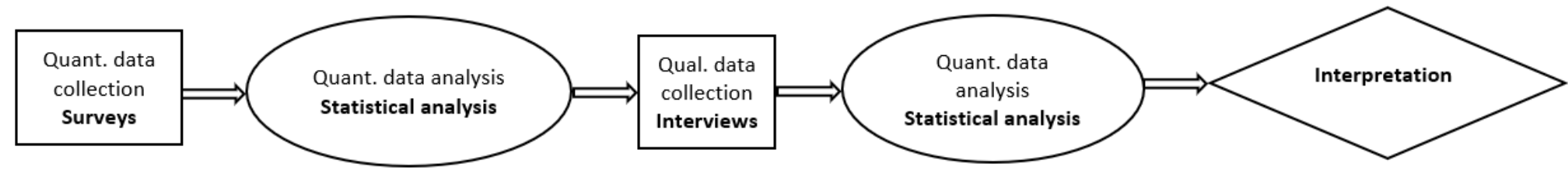

Figure 1. Sequential Explanatory Mixed Methods approach

This study utilized a sequential explanatory mixed methods approach to explore academics' beliefs and experiences with sustainability in their working space (Clark \& Creswell, 2008). Under the explanatory mixed methods approach, data collection and analysis are processed in two phases, figure 1. Initially, the quantitative responses from the online survey were analyzed, and, in turn, the quantitative results informed the interview protocol, aiming to further explore and explain the quantitative responses. (Creswell \& Plano-Clark, 2007). The interviewees were participants who had already completed the survey. Mixed methods have been used widely in social sciences as a way of combining both quantitative and qualitative methods 
in data collection and data analysis. Quantitative data were collected through an online survey and qualitative data by conducting phone interviews; both methods are explained in detail below.

\subsection{Participants}

To identify potential participants, an Excel spreadsheet was built with the email addresses of 8,694 academics. The authors identified those individuals by browsing the websites of university departments for people who fulfilled the criteria for this study, as explained below. A modified Dillman et al. (2014) survey distribution method was employed. The survey was distributed through Qualtrics XM, an online software, with four contact points used for soliciting participation (Dillman et al., 2014). Contact 1 included a pre-notice email providing an in-depth explanation of the study, including the study information and recruitment information documents. In Contact 2, participants received individualized links to the survey through Qualtrics. Contacts 3 and 4 served as reminders to individuals who did not participate in the survey yet.

Participants targeted are faculty members in US-based universities from the Northeastern and Midwestern regions of the US. In total, 112 universities were contacted in the Midwest and 85 universities in the Northeast through their departments of interest. The academic duties of the faculty members involved being teachers, researchers, or both. Their academic ranking included professors, assistant professors, associate professors, lecturers, postdocs, and adjuncts. An additional participation criterion to the above included that their teaching or research is directly or indirectly linked to environmental issues. An attempt was made to include faculty members from the humanities, natural sciences, social sciences, and engineering. Table 1 below shows some of the relevant characteristics of the participants. 
Table 1. Participants' characteristics.

\begin{tabular}{cc}
\hline & N \\
\hline Faculty rank \\
Professor & 229 \\
Assistant professor & 135 \\
Associate professor & 146 \\
Other* & 123
\end{tabular}

Academic engagement

$\begin{array}{cc}\text { Teaching } & 243 \\ \text { Research } & 277 \\ \text { Both } & 95 \\ \text { Other } & 18 \\ \text { Gender* } & \\ \text { Male } & 343 \\ \text { Female } & 252\end{array}$

Prefer not to answer $\quad 12$

Higher academic degree**

$\begin{array}{cc}\text { PhD } & 559 \\ \text { Master } & 37 \\ \text { Bachelor's } & 3 \\ \text { Other } & 8\end{array}$

*: Includes postdocs, adjuncts and lecturers.

**: 26 missing. 


\subsection{Instrumentation}

\subsubsection{Survey}

This study is partially based on an online survey that was distributed through Qualtrics XM to the email addresses of 8,694 individual academics. In total, 696 responses were received, and 633 were deemed as appropriate for the analysis of this study, resulting in a response rate of 7.3\%, which is lower than similar past studies (Carlton et al., 2015). From the 633 responses, 169 were "social scientists," 370 were "natural scientists," 35 were from the "humanities," 57 were "engineers," and 2 were "other." The purpose of the survey was to collect demographic data and responses about their role in EB in their workplace. The latter was achieved through the use of a scale developed and validated by Boiral and Paillé (2012), which has three factors: eco-helping, eco-civic engagement, and eco-initiatives. This study's factor analysis did not reveal the suggested three factors, so the scale was analyzed as one factor.

To analyze the data from the survey, a Welch analysis of variance (ANOVA) and an independent samples $t$-test were conducted. The statistical software SPSS version 26 was used to conduct all statistical tests. Welch ANOVA was used to account for unequal variances (Delacre, Leys, Mora, \& Lakens, 2019). According to De Winter and Dodou (2010), a $t$-test can be used for the analysis of a five point Likert scale, as it has the same power with the non-parametric Mann Whitney-Wilcoxon test.

Prior to conducting the ANOVA tests, the authors checked for possible violations of the following three assumptions: 1) normality, 2) equal variances, and 3) the independence of samples. The normality assumption was violated with $\mathrm{p}<0.05$, but because of the robustness of 
ANOVA and the sufficiently large sample size, I continued with the analysis. The Levene's Homogeneity test was significant, so the non-parametric Kruskal-Wallis test was also performed (Sapiains, Beeton, \& Walker, 2016). Finally, the independence of the responses was ensured through the survey distribution methods. Both the Welch ANOVA and the Kruskal-Wallis results were the same, so the Welch ANOVA results were reported (Sapiains et al., 2016). Overall, literature supports the use of ANOVA with Likert scales that are of unequal variances or do not necessarily meet the normality criteria (Norman, 2010). The ANOVA tests that showed statistically significant differences are further analyzed with Tukey's HSD (Honestly Significant Difference) test to identify the groups that were statistically different from each other.

\subsubsection{Interviews}

Potential interview participants were contacted after we conducted preliminary analysis of the survey responses. We chose to conduct interviews with participants whose survey responses could, if expanded in more detail, helped us further understand their opinions on sustainability in their working space. In total, 29 interviews were conducted, but one was deemed inappropriate for this analysis because their research interest did not match the criteria of this study. The final 28 interviews were transcribed verbatim and coded through an iterative process (Tracy, 2012). The analysis was performed with the online mixed methods analytical software Dedoose version 8.3.17.

The aim of the interviews was to explore academics' perceptions of work-related sustainability actions and explore potential barriers keeping academia from being more sustainable.

\section{Results}

\subsection{Quantitative}


This study used the instrument developed by Boiral and Paillé (2012) to measure the organizational citizenship behavior for the environment amongst academics, $n=633$. The independent variables for this study included: (a) university location, (b) faculty ranking, (c) field of study, (d) political views, and e) primary academic duties (teaching or research). The dependent variable was the OCBE score. To calculate the OCBE score, the researcher took the summative score of each participant's responses in the instrument used and performed inferential statistics.

To examine differences in OCBE between academics in Northeastern and Midwestern universities, an independent sample $t$-test was performed. The results of this test indicated that there is a significant difference in OCBE between the two groups $t(632)=-2.215, p=.027$. These results indicate that academics in Northeastern universities $(M=21.69, \mathrm{SD}=6.43)$ engage more in sustainability practices in their working place compared to academics in Midwestern universities $(\mathrm{M}=22.92, \mathrm{SD}=7.489)$. Lower $\mathrm{M}$ scores indicate higher OCBE.

A one-way Welch ANOVA was conducted to compare the effect of faculty ranking on the reported OCBE score. There is a statistically significant effect of faculty ranking on the reported OCBE score at $\mathrm{p}<.05$ level for the four conditions $F(3,629)=6.322, p=.001$ (see Table 2). Post hoc comparisons using the Games Howell test indicated that the mean score for "Professors" $(M=20.80, S D=6.448)$, is significantly different from "Assistant professor" $(M=23.71$, $\mathrm{SD}=7.155)$, and "Other" $(\mathrm{M}=22.89, \mathrm{SD}=6.051)$. There are no significant differences amongst the groups “Associate professors," "Assistant professor," and "Other." Lower M scores indicate higher OCBE.

Table 2. Welch ANOVA results for OCBE. 


\begin{tabular}{rccc}
\hline Independent variable & $\mathbf{F}$ & Significance & $\mathbf{N}$ \\
\hline Faculty ranking & 6.322 & 0.001 & 633 \\
Field of study & 1.898 & 0.134 & 633 \\
Academic duties & 4.883 & 0.004 & 633 \\
Political views & 4.981 & 0.002 & 608 \\
\hline \multicolumn{4}{c}{$\mathrm{p}<0.005}$.
\end{tabular}

A separate one-way Welch ANOVA was conducted to compare the effect of the field of study on the reported OCBE score. No significant differences were found for the five conditions $F(4,628)=1.898, p=.134($ see Table 2$)$.

A third one-way Welch ANOVA was conducted to compare the effect of academic duties on the OCBE score. The test indicated a statistically significant effect of academic duties on the reported OCBE score at $\mathrm{p}<.05$ level for the four conditions $F(3,629)=4.883, p=.004$ (see Table 2). The Games Howell test indicated that the mean score for "Both researcher and teacher" $(\mathrm{M}=$ 20.96, $\mathrm{SD}=6.218)$, was significantly different from "Researcher" $(\mathrm{M}=23.22, \mathrm{SD}=7.293)$. Lower M scores indicate higher OCBE. No other significant differences were found amongst the other conditions.

A final one-way Welch ANOVA was performed to compare the effect of political views on the OCBE score. The test indicated a statistically significant effect of political views on the reported OCBE score at $\mathrm{p}<.05$ level for the five conditions $F(4,603)=4.9811, p=.002$ (see Table 2). The Games-Howell test indicated that the mean score for "Conservative" $(M=28.96$, $\mathrm{SD}=10.348)$, was significantly different from "Moderate" $(\mathrm{M}=22.63, \mathrm{SD}=7.114)$, "Liberal" $(\mathrm{M}=22.29, \mathrm{SD}=5.829)$ and "Very Liberal" $(\mathrm{M}=20.90, \mathrm{SD}=6.742)$. Lower $\mathrm{M}$ scores indicate higher OCBE of an individual. 


\subsection{Qualitative}

To further understand the findings from the quantitative analysis, we conducted open-ended interviews with 28 of the academics who responded to the survey. In the parentheses after the quote, the academic discipline of each participant is noted with SS for social scientist, $\mathrm{H}$ for humanities, E for engineers, and NS for natural scientists. There is also a number indicating the different participants.

From the analysis of the interviews for this study, three themes emerged. The themes and their associated codes are presented in Table 3.

Table 3. Interviews' themes and codes

Personal Environmental behaviors Differences amongst Work associated at work academics in environmental sustainability behaviors

Pro-environmental behaviors $\quad$ Monetary issue (10) Teaching (25)

Travelling (2) No difference (4) $\quad$ Service (22)

Anti-environmental behaviors

Activism (4)

Office related operation (9)

Research (4)

Travelling (21)

Seminars (3)

Discuss with colleagues

\section{Theme 1-Personal environmental behaviors at work:}

Most academics identified a variety of anti-environmental and pro-environmental behaviors they engaged in while at work. Although some were cognizant of their environmental impacts, 
they continued engaging in these behaviors, as they did not have control over some of them. Travelling was identified as both an PEB and an AEB. Another code that emerged was the daily operations of an office, including printing, computer usage, and heating the offices. Following are interview excerpts depicting some of the participants' position:

“[...] there are expectations of travel to conferences on timeframes that are prohibitive of, of driving, right, there's a lot of pressure to fly, and sometimes you know, what is feasible what's technically feasible versus what is practical can, can be different to that, you know."

"I have to drive to campus, and you know, I wish I could, I wish I could, I wish I had mass transit, but I don't” (H1)

"I am on my computer a lot, so obviously that uses energy [...], there is heating the building, but that I think would be related to any working environment” (NS1).

\section{Theme 2-Differences amongst academics in environmental behaviors:}

Different opinions were expressed about the role of academic ranking and sustainability. Most participants said that lower ranking faculty members are less sustainable because of the heavy workload they have, earning less money, and having less of an ability to influence/make changes because of their junior position.

"I bought a house not too far from campus and I actually bicycle to work every day. I do not use a car every day. And that was, you know, and as you know, most college towns to try to live near campus, if you do not have the money, you cannot do that. [...]. So, in this sense, having this kind of position [professor] in academia and having more stability in having more income I can, you know, use that in a way to, to help me be a little more sustainable. I think so. [...]Certainly, I have more academic freedom now 
than when I, I was an assistant professor. So, I would say yes, yes. I mean it is not a huge change, but yes" (NS2).

"Yeah. And, you know, after I got tenure, I decided I did not like to travel as often as I was forced to. And so, I, uh, [...] wrote a book instead, instead of, you know, traveling to the conferences. It is, that is, you know, that is that is a big concern in architecture. You know, traveling is important because we can see other spaces and other [...]. And it is, you know, I, I hate the idea of it (flying). And I, and I try and limit it as much as possible. So yeah, for, for several years in there, I really, I, I tried to not go as much as I could, and so for several years I didn't go by plane anywhere" (H2).

There were also four individuals who did not perceive any barriers in being more sustainable in their academic life.

"Um, no. Uh, I was trying to think there was a way in which that would affect it. No. Um, no, I don't think there's really that much difference” (E1).

"I don't think I have seen any change in my own personal behavior. I think I tend to be somewhat more active than I would have been when I started 19 years ago in trying to, you know, reduce climate change impact. But I think it is pretty constant. It is just as the issue has gotten more important and salient for me. I don't think it's related to my academic rank however" (H3).

\section{Theme 3-Work associated sustainability:}

This theme described the different ways academics were involved with sustainability in their working space. Most participants reported doing so through teaching (25) and serving in different committees (22), while some mentioned lack of time as a barrier. 
"I teach environmental history and I teach when I can, I can't do it too often, but I teach environmental arts when I can" (H4). "I've done a lot of, um, outreach and engagement on climate change and climate change science. I am also travelling in New York state and have, spoken at youth climate summit, and then I also, I, oh, I, I run a podcast with students about climate change" (SS1).

"I've tied them in with my research agendas of course, but, you know, in academia we have no free time, so you have to figure out, um, how to make it. I have combined my teaching, my research and my service and build that service in the community, with community gardens and policy groups and, that I tie in with student research, which is part of my class. You know, I build classes around student research on these issues, and I teach a research methods class, I teach a class on sustainability in rural America and I serve on the policy advisor for the center for rural affairs, you know, so it all, it, it all set up so that everything I do compliments and the students know what I'm about" (SS2).

\section{Discussion}

Results from this study's mixed method analysis revealed several differences and similarities amongst participants' OCBE score and their role as academics in sustainability. The quantitative analysis indicates that "Professors" $(\mathrm{M}=20.8)$ in this study reported lower OCBE scores compared to other faculty rankings (e.g., "Assistant professors" $(\mathrm{M}=23.71)$ and "Others" $(\mathrm{M}=22.89))$; low OCBE scores result in high levels of EB. Linking findings from the qualitative analysis with the above, we can see that, although there are diverse opinions on whether faculty ranking can influence one's EB, the majority of participants suggested that there is a difference with senior faculty members being more sustainable than junior faculty members. This disparity could be attributed to professors not flying to conferences because of their status, as well as 
having the financial capacity of living closer to campus, allowing them to walk or ride a bike instead of driving a car. Although most junior faculty members recognized that flying has negative consequences for the natural environment, they continued flying due to the career benefits it offers. Similar results have been reported by Cohen, Higham, and Cavaliere (2011), who explored the reduction of excessive flying amongst tourists in which participants reported dilemmas between the benefits of travelling and the impact it has on climate.

Few individuals also suggested that EB depend on an individual's personal ideologies and beliefs and that their position in academia would not make a difference. No similar studies were found to compare other industries to academia to identify whether there is a difference in the OCBEs among employees' ranks. Pertinent literature in OCBEs suggests that senior management's beliefs and attitudes about environmental issues associated with their power dynamics can have an impact on whether the company will or will not adopt sustainable practices (Priyankara, Luo, Saeed, Nubuor, \& Jayasuriya, 2018; Robertson \& Barling, 2013; Sawang \& Kivits, 2014; Walls \& Berrone, 2017). Future research should explore how heads of departments and administration can foster a working environment that could bolster the PEB of their academics.

The majority of respondents were conscious of several AEB they engaged in while working, but they continued engaging in them. These finding align with Festinger (1957) theory of cognitive dissonance. Participants chose to justify their behaviors as a mechanism to reduce their cognitive dissonance while engaging in the effort justification paradigm of cognitive dissonance (Harmon-Jones, 2002; Harmon-Jones \& Mills, 1999). The only two recent studies identified that explore academics' cognitive dissonance in a similar context to this study are by Schrems and Upham (2020) and by Nursey-Bray et al. (2019), whose studies reported that academics 
exhibited cognitive dissonance for flying but reported behavioral changes, denial of control, and denial of responsibility as a means to reconcile with their cognitions.

The OCBE results, measuring an individual's environmental behaviors, suggest that individuals who reported liberal political affiliations were more sustainable $(\mathrm{M}=22.29)$ in their working environment compared to conservative affiliated faculty members $(M=28.96)$. Lower OCBE scores indicate higher environmental behaviors. Although there are studies on political affiliations and sustainability in different contexts, such as farmers and laypeople (Egan \& Mullin, 2017; Liu, Smith, \& Safi, 2014; Ziegler, 2017), this study appears to be the first to explore the relationship between political views and sustainability in an academic working environment. In addition, academics whose duties included both research and teaching $(M=20.96)$ reported higher sustainability through their OCBE score compared to academics that only engaged in research $(\mathrm{M}=23.22)$.

This study's data suggest that the area where the university is located, plays an important role in the sustainability actions of the faculty members. Looking at the political map of the U.S., we can see that the Northeastern region of the U.S. is more liberal compared to the Midwestern region (Electoral map, 2016). In addition, some studies suggest that individuals supporting conservative ideologies were less likely to support policies to bolster sustainability compared to liberal oriented individuals (Ziegler, 2017). Conversely, Gradus et.al, (2019), suggested that local political affiliation did not play a role in adopting a pay as you go recycling program that helps increase recycling efficiency. Future exploration is needed to further understand this finding and identify whether this discrepancy could be due to liberal states being more in favor of sustainability policies compared to conservative states. 
When participants were asked how they were involved with sustainability at the university, the majority reported through their teaching and their participation in different committees. Both the quantitative and the qualitative data in this study suggest that the lack of time and the heavy workload only allows certain academics to engage in voluntarily activities to promote sustainability. In accordance with the tenets of OCBE, the voluntary aspect of engaging in sustainable behaviors is of high priority, but this study's data indicate that the voluntary aspect is mostly evident with higher ranked academics and not junior faculty members.

\section{Conclusions and limitations}

The aim of this study was to explore the environmental sustainability of faculty members at work and examine the potential barriers they face to being more sustainable. The importance of this study lays in the fact that it expands our understanding in an existing but under-researched topic. Findings of this study suggest that there are substantial differences in the EB among academics and their faculty ranking. In addition, although most faculty members are cognizant of the consequences of their actions, they still engage in them for reasons that are mostly associated with their academic careers. Interview responses suggest that full professors and tenured faculty members are more likely to halt their own AEB compared to junior faculty members. It is important that academia changes its systemic way of evaluating and assessing academics, as the current system relies on conference presentations and a high volume of work, which prohibit most junior faculty members from being more sustainable. The sustainability beliefs and attitudes of the upper-level management plays an important role in an organization's sustainability, which could also be the case with the heads of departments in universities, however, further research is needed. 
Although this study is not grounded in any theory, the theory of cognitive dissonance is being used as a reference point to analyze and make sense of the data. Analysis of the interviews suggests that experts can experience cognitive dissonance in relation to their field of expertise. This is an important finding, as it strengthens the argument that environmental knowledge does not always lead to environmental behaviors. As other academics have suggested, it is important to reconsider the importance of travelling to conferences and transition to a model that requires less travelling, thus minimizing associated environmental impacts. There are certain areas that make academia a less sustainable working environment, but there are also several areas that potentially off-set the anti-environmental behaviors, such as the research they produce and the information they share with students and the public.

Overall, this study provides an important understanding of the barriers that faculty members are experiencing in acting in a more sustainable manner. The implications of the findings are twofold. Primarily, it may act as a reminder to academia on the accountability that we as academics have towards the public and our students. Secondary, it could inform universities in adopting policies to make academia more sustainable and bolster academics' environmental behaviors.

Academia is often seen as a point of reference for societies; thus it is important for academia as an institution to lead the way in sustainable working spaces and promote societal, environmental and economical friendly practices.

This study does not aim to generalize the findings but rather to inform us on the current situation and help with future studies. This study is limited because the quantitative data were self-reported by the participants. Another limitation is that responses on the online survey were 
disproportionally weighted, with the majority from natural scientists and the minimum from the humanities.

The data suggests that academics only engage in sustainability through their teaching and research, so future work could explore academics' influence on their departments in choosing service duties related to sustainability.

Acknowledgments: The authors would like to thank all the participants that provided their valuable time and experiences to this study, as well as the reviewers that strengthened this paper with their suggestions and recommendations. 


\section{References}

Adam, M., The role of human resource management (HRM) for the implementation of sustainable product-service systems (PSS)_an analysis of fashion retailers. Sustainability, 2018. 10(7): p. 2518.

Anwar, N., et al., Green Human Resource Management for organisational citizenship behaviour towards the environment and environmental performance on a university campus. Journal of Cleaner Production, 2020. 256: p. 120401.

Ateş, H., Merging Theory of Planned Behavior and Value Identity Personal norm model to explain pro-environmental behaviors. Sustainable Production and Consumption, 2020. 24: p. 169-180.

Baer, H.A., The elephant in the sky: On how to grapple with our academic flying in the age of climate change. Anthropology Today, 2019. 35(4): p. 21-24.

Bekessy, S. and M. Burgman, Universities and sustainability. TELA: Environment, economy and society, 2003. 11: p. 1-41.

Bellou, C., V. Petreniti, and C. Skanavis, Greening the campus intentions: a study of the University of the Aegean non-academic staff. International Journal of Sustainability in Higher Education, 2017.

Blok, V., et al., Encouraging sustainability in the workplace: a survey on the pro-environmental behaviour of university employees. Journal of cleaner production, 2015. 106: p. 55-67.

Boiral, O. and P. Paillé, Organizational Citizenship Behaviour for the Environment: Measurement and Validation. Journal of Business Ethics, 2012. 109(4): p. 431-445.

Bossdorf, O., M. Parepa, and M. Fischer, Climate-neutral ecology conferences: just do it! Trends in ecology \& evolution, 2010. 25(2): p. 61. 
Brinkhurst, M., et al., Achieving campus sustainability: top-down, bottom-up, or neither? International Journal of Sustainability in Higher Education, 2011.

Burke, I.C., Travel trade-offs for scientists. Science, 2010. 330(6010): p. 1476-1476.

Carlton, J.S., et al., The climate change consensus extends beyond climate scientists. Environmental Research Letters, 2015. 10(9): p. 094025.

Caset, F., K. Boussauw, and T. Storme, Meet \& fly: Sustainable transport academics and the elephant in the room. Journal of transport geography, 2018. 70: p. 64-67.

Chekima, B., et al., Sustainable consumption: the effects of knowledge, cultural values, environmental advertising, and demographics. International Journal of Sustainable Development \& World Ecology, 2016. 23(2): p. 210-220.

Choong, Y.-O., et al., Green work climate and pro environmental behavior among academics:. The mediating role of harmonious environmental passion International Journal of Management Studies, 2020. 26(2): p. 77-97.

Chu, K.M., Mediating influences of attitude on internal and external factors influencing consumers' intention to purchase organic foods in China. Sustainability, 2018. 10(12): p. 4690.

Clark, V.L.P. and J.W. Creswell, The mixed methods reader. 2008: Sage.

Cohen, S.A., J.E. Higham, and C.T. Cavaliere, Binge flying: Behavioural addiction and climate change. Annals of Tourism Research, 2011. 38(3): p. 1070-1089.

Creswell and Plano-Clark, Desiging and Conducting : Mixed Methods Research. 2007, Los Angeles, CA: Sage. 
Daily, B.F., J.W. Bishop, and N. Govindarajulu, A conceptual model for organizational citizenship behavior directed toward the environment. Business \& Society, 2009. 48(2): p. 243-256.

De Groot, J.I. and L. Steg, Value orientations to explain beliefs related to environmental significant behavior: How to measure egoistic, altruistic, and biospheric value orientations. 2008. 40(3): p. 330-354.

De Silva, D.G. and R.A. Pownall, Going green: does it depend on education, gender or income? Applied Economics, 2014. 46(5): p. 573-586.

De Winter, J. and D. Dodou, Five-Point Likert Items: t test versus Mann-Whitney-Wilcoxon (Addendum added October 2012). Practical Assessment, Research, and Evaluation, 2010. 15(1): p. 11.

Delacre, M., et al., Taking parametric assumptions seriously: Arguments for the use of Welch's F-test instead of the classical F-test in one-way ANOVA. International Review of Social Psychology, 2019. 32(1).

Desiere, S., The carbon footprint of academic conferences: Evidence from the 14th EAAE Congress in Slovenia. EuroChoices, 2016. 15(2): p. 56-61.

Dillman, D.A., J.D. Smyth, and L.M. Christian, Internet, phone, mail, and mixed-mode surveys: the tailored design method. 2014: John Wiley \& Sons.

Dolnicar, S., L. Knezevic Cvelbar, and B. Grün, Do pro-environmental appeals trigger proenvironmental behavior in hotel guests? Journal of Travel Research, 2017. 56(8): p. 988997.

Dunlap, R.E., J.K. Grieneeks, and M. Rokeach, Human values and pro-environmental behavior. 1983. 
Durr, E., J. Bilecki, and E. Li, Are Beliefs in the Importance of Pro-Environmental Behaviors Correlated with Pro-Environmental Behaviors at a College Campus? Sustainability: The Journal of Record, 2017. 10(3): p. 204-210.

Egan, P.J. and M. Mullin, Climate change: US public opinion. Annual Review of Political Science, 2017. 20: p. 209-227.

Electoral Map and Presidential Election Results 2016. Political Maps. (2016, November 9). http://politicalmaps.org/2016-electoral-map/. Accessed 25/5/2021

Fang, W.-T., E. Ng, and Y.-S. Zhan, Determinants of pro-environmental behavior among young and older farmers in Taiwan. Sustainability, 2018. 10(7): p. 2186.

Fawehinmi, O., et al., Assessing the green behaviour of academics. International Journal of Manpower, 2020.

Festinger, L., A theory of cognitive dissonance: Stanford Univ Pr. Fornell, C., \& Larcker, DF (1981). Evaluating structural equation models with, 1957.

Fonseca, A., et al., The state of sustainability reporting at Canadian universities. International Journal of Sustainability in Higher Education, 2011.

Fox, H.E., et al., Why do we fly? Ecologists' sins of emission. Frontiers in Ecology and the Environment, 2009. 7(6): p. 294-296.

Gadeikienè, A., et al., Sustainable consumption behaviour spill-over from workplace to private life: Conceptual framework. Polish Journal of Management Studies, 2019. 19.

Gardner, G.T. and P.C. Stern, Environmental problems and human behavior. 1996: Allyn \& Bacon.

Gilal, F.G., et al., Promoting environmental performance through green human resource management practices in higher education institutions: A moderated mediation model. 
Corporate Social Responsibility and Environmental Management, 2019. 26(6): p. 15791590.

Glover, A., Y. Strengers, and T. Lewis, The unsustainability of academic aeromobility in Australian universities. Sustainability: Science, Practice and Policy, 2017. 13(1): p. 1-12.

Hameed, Z., et al., Do green HRM practices influence employees' environmental performance? International Journal of Manpower, 2020.

Hameed, Z., et al., Do green HRM practices influence employees' environmental performance? International Journal of Manpower, 2020.

Harmon-Jones and J.E. Mills. Cognitive dissonance: Progress on a pivotal theory in social psychology. in Scientific Conferences Program, 1997, U Texas, Arlington, TX, US. American Psychological Association.

Harmon-Jones, A cognitive dissonance theory perspective on persuasion. The persuasion handbook: Developments in theory and practice, 2002. 101.

Hazal Aral, Ö. and J. López-Sintas, A Comprehensive Model to Explain Europeans' Environmental Behaviors. Sustainability, 2020. 12(10): p. 4307.

Jabbour, C.J.C. and F.C.A. Santos, The evolution of environmental management within organizations: toward a common taxonomy. Environmental Quality Management, 2006. 16(2): p. 43-59.

Janmaimool, P. and S. Khajohnmanee, Roles of environmental system knowledge in promoting university students' environmental attitudes and pro-environmental behaviors. Sustainability, 2019. 11(16): p. 4270. 
Klaniecki, K., J. Leventon, and D.J. Abson, Human-nature connectedness as a 'treatment'for pro-environmental behavior: making the case for spatial considerations. Sustainability Science, 2018. 13(5): p. 1375-1388.

Kollmuss, A. and J. Agyeman, Mind the gap: why do people act environmentally and what are the barriers to pro-environmental behavior? Environmental education research, 2002. 8(3): p. 239-260.

Kurisu, K., What Are Pro-Environmental Behaviors (PEBs)?, in Pro-environmental Behaviors. 2015, Springer. p. 1-26.

Lester, B., Greening the meeting. 2007, American Association for the Advancement of Science.

Liu, Z., W.J. Smith, and A.S. Safi, Rancher and farmer perceptions of climate change in Nevada, USA. Climatic change, 2014. 122(1-2): p. 313-327.

Luu, T.T., CSR and organizational citizenship behavior for the environment in hotel industry. International Journal of Contemporary Hospitality Management, 2017.

Meyer, A., Heterogeneity in the preferences and pro-environmental behavior of college students: the effects of years on campus, demographics, and external factors. Journal of Cleaner Production, 2016. 112: p. 3451-3463.

Muster, V., Companies promoting sustainable consumption of employees. Journal of consumer policy, 2011. 34(1): p. 161-174.

Niyomdecha, L. and K.K. Yahya, Examining The Relationship Between Human Resource Managemnt Practices And Organizational Citizenship Behavior For Environment Among Administrative Staff In A Thailand University. Sains Humanika, 2019. 11(2-2).

Norman, G., Likert scales, levels of measurement and the "laws" of statistics. Advances in health sciences education, 2010. 15(5): p. 625-632. 
Nursey-Bray, M., et al., The fear of not flying: achieving sustainable academic plane travel in higher education based on insights from south Australia. Sustainability, 2019. 11(9): p. 2694.

Ones, D.S. and S. Dilchert, Environmental sustainability at work: A call to action. Industrial and Organizational Psychology, 2012. 5(4): p. 444-466.

Ostrom, E., A general framework for analyzing sustainability of social-ecological systems. Science, 2009. 325(5939): p. 419-22.

Porter, M.E. and C. Van der Linde, Toward a new conception of the environmentcompetitiveness relationship. Journal of economic perspectives, 1995. 9(4): p. 97-118.

Priyankara, H.P.R., et al., How does leader's support for environment promote organizational citizenship behaviour for environment? A multi-theory perspective. Sustainability, 2018. 10(1): p. 271.

Programme, U.N.E., Sustainable Consumption and Production: A Handbookfor Policymakers (Global Edition). 2016: UN.

Pryce-Jones, J., Happiness at work: Maximizing your psychological capital for success. 2011: John Wiley \& Sons.

Ramus, C.A. and A.B. Killmer, Corporate greening through prosocial extrarole behaviours-a conceptual framework for employee motivation. Business Strategy and the Environment, 2007. 16(8): p. 554-570.

Robertson, J.L. and J. Barling, Greening organizations through leaders' influence on employees' pro-environmental behaviors. Journal of organizational behavior, 2013. 34(2): p. 176194. 
Sapiains, R., R.J. Beeton, and I.A. Walker, Individual responses to climate change: Framing effects on pro-environmental behaviors. Journal of Applied Social Psychology, 2016. 46(8): p. 483-493.

Sawang, S. and R.A. Kivits, Greener workplace: understanding senior management's adoption decisions through the Theory of Planned Behaviour. Australasian Journal of Environmental Management, 2014. 21(1): p. 22-36.

Schrems, I. and P. Upham, Cognitive Dissonance in Sustainability Scientists Regarding Air Travel for Academic Purposes: A Qualitative Study. Sustainability, 2020. 12(5): p. 1837.

Shultz, T.R. and M.R. Lepper, Cognitive dissonance reduction as constraint satisfaction. Psychological review, 1996. 103(2): p. 219.

Srun, P. and K. Kurisu, Internal and External Influential Factors on Waste Disposal Behavior in Public Open Spaces in Phnom Penh, Cambodia. Sustainability, 2019. 11(6): p. 1518.

Staddon, S.C., et al., Intervening to change behaviour and save energy in the workplace: A systematic review of available evidence. Energy Research \& Social Science, 2016. 17: p. 30-51.

Taylor, M.R., A.J. Lamm, and L.K. Lundy, Using Cognitive Dissonance to Communicate with Hypocrites About Water Conservation and Climate Change. Journal of Applied Communications, 2017. 101(3).

Thogersen, J., Cognitive dissonance and sustainable consumption. ACR Asia-Pacific Advances, 2002.

Tosti-Kharas, J., E. Lamm, and T.E. Thomas, Organization or environment? Disentangling employees' rationales behind organizational citizenship behavior for the environment. Organization \& Environment, 2017. 30(3): p. 187-210. 
Tracy, S.J., Qualitative research methods: Collecting evidence, crafting analysis, communicating impact. 2012, Malden, MA: John Wiley \& Sons.

Walls, J.L. and P. Berrone, The power of one to make a difference: How informal and formal CEO power affect environmental sustainability. Journal of Business Ethics, 2017. 145(2): p. 293-308.

Yang, S., Y. Zhang, and D. Zhao, Who exhibits more energy-saving behavior in direct and indirect ways in china? The role of psychological factors and socio-demographics. Energy Policy, 2016. 93: p. 196-205.

Yuriev, A. and W. Sierra-Barón, Exploring sustainability cross-culturally: Employees' beliefs on green behaviors. Sustainable Development, 2020.

Ziegler, A., Political orientation, environmental values, and climate change beliefs and attitudes: An empirical cross country analysis. Energy Economics, 2017. 63: p. 144-153.

Ziker, J., How professors use their time: Faculty time allocation. The Blue Review, 2014.

BIO:

Kostas Stavrianakis is a recent $\mathrm{PhD}$ graduate whose research focuses on environmental behaviors and climate change. He is currently a research fellow at Robert Gordon University, Scotland, exploring communities' awareness and perceptions of carbon capture, utilization and storage technologies.

\section{William D. Ramos, Ph.D.}

Residing within the Department of Health \& Wellness Design under the Indiana University School of Public Health as an Associate Professor, Dr. Ramos' research focuses on examining the impact of both built and natural environments on the human experience. In addition, he also engages in the legal aspects of aquatics in the role of expert consultant. 